\title{
A CROSS SECTIONAL STUDY TO FIND OUT QUALITY OF LIFE OF URBAN PROFESSIONAL PHYSIOTHERAPISTS
}

\author{
Nikita Vishnu Sawant ${ }^{* 1}$, Jui Dave ${ }^{2}$, Gauri Kulkarni ${ }^{3}$. \\ ${ }^{* 1}$ M.P.Th (Neurophysiotherapy), Terna Physiotherapy College, Sector 12, Nerul, Navi Mumbai- 400 \\ 706, India. \\ 2 Professor, Terna Physiotherapy College, Sector 12, Nerul, Navi Mumbai- 400 706, India. \\ ${ }^{3}$ Associate Professor, Modern College of Physiotherapy, Shivajinagar, Pune, India.
}

\section{ABSTRACT}

Background: The present study is the survey to gather information regarding quality of life (QOL) and its influencing factors among urban professional physiotherapists. AIM: This study is designed to help us as a community to understand our problems and address them to have better work- life balance.

Objective: This study is solely done to highlight problems faced by physiotherapists, which should be tackled as earliest, thereby helping in professional growth. METHOD: Cross sectional study.

Result: Average mean score of QOL of urban professional physiotherapists is $\mathbf{5 2 . 3 8}$ while most urban professional physiotherapists have QOL score (mode) of 53.85 with median of 52.44 . Conclusion: This study concludes that QOL scores of urban professional physiotherapists remain mostly on lower side. Item analysis showed that emotional problem domain is severely affected followed by physical health domain.

KEY WORDS: Quality of life, Urban professional physiotherapist.

Address for correspondence: Dr. Nikita Vishnu Sawant, M.P.Th (Neurophysiotherapy), Terna Physiotherapy College, Sector 12, Nerul, Navi Mumbai- 400 706, India.

E-Mail: nikitasawant342@gmail.com

Access this Article online

Journal Information

Quick Response code

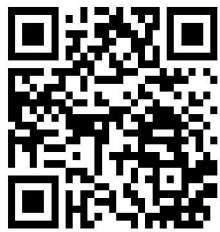

DOI: $10.16965 /$ ijpr.2019.119

International Journal of Physiotherapy and Research

ISSN (E) 2321-1822 | ISSN (P) 2321-8975

https://www.ijmhr.org/ijpr.html

DOI-Prefix: https://dx.doi.org/10.16965/ijpr

Article Information

Received: 06 Mar 2019

Peer Review: 06 Mar 2019

Revised: None
Accepted: 01 Apr 2019

Published (O): 20 Apr 2019

Published (P): 11 Jun 2019

\section{BACKGROUND}

'Adding life to years' slogan laid down by WCPT for World physiotherapy Day on $8^{\text {th }}$ September 2018 truly represent us. While treating and taking care of patients, most of the time our quality of life (QOL) goes unnoticed affecting our professional and family commitments, community participation and last but not the least, our quantity of productive life.Quality of life is a broader concept and is concerned with whether influencing factors limits a person's ability to fulfil a normal role. Perception of quality of life varies between individuals and is dynamic within them. People with different expectations will report that they have a different quality of life even when they have the same condition [1]. The quality of life of urban professional physiotherapists is majorly influenced by primary factors like workplace stress, working hours, teamwork, deadlines, maintenance of clinical records, transport mode, pollution, networking facilities available and lack of time for physical exercise [2]. Now, these primary factors affecting QOL in urban adult professional physiotherapists can be divided into 2 categories i.e. physical and mental stressors. Stress is a universally used and well known world in psychological, social and professional settings. Eustress and distress 
describes the positive and negative aspects of stress in person's life [3].

Now in medical profession like physiotherapy, the effect of these physical and mental stressors could be high as compare to general population due to commitments and challenges of their job ultimately affecting their quality of life. Thus, this study is designed to make us aware as a community regarding the stressors influencing our quality of life and acts as a baseline for the formation of permanent remedy against it.

\section{MATERIALS AND METHODS}

Study type: Cross sectional study Study design: A survey

Sample size: 100

Sampling techniques: Snow ball sampling Duration: 12 months

Sampling frame: Samples were collected from hospitals $\&$ physiotherapy clinics in $\&$ around Pune, 100 professional physiotherapists who were full time practitioner and have more than one year of experience were selected from clinics and hospitals in and around Pune. Professional Physiotherapist suffering from any medical and surgical condition that can affect their quality of life was excluded from study.

\section{Material:}

- Pen

- Paper

- Consent form

- Quality of life questionnaire (SF-36)

After the consent taken from respective professional physiotherapist, they were asked to fill QOL questionnaire and data were analyzed statistically.

\section{RESULT}

Graph 1:

Classification of candidates according to SF- 36 score

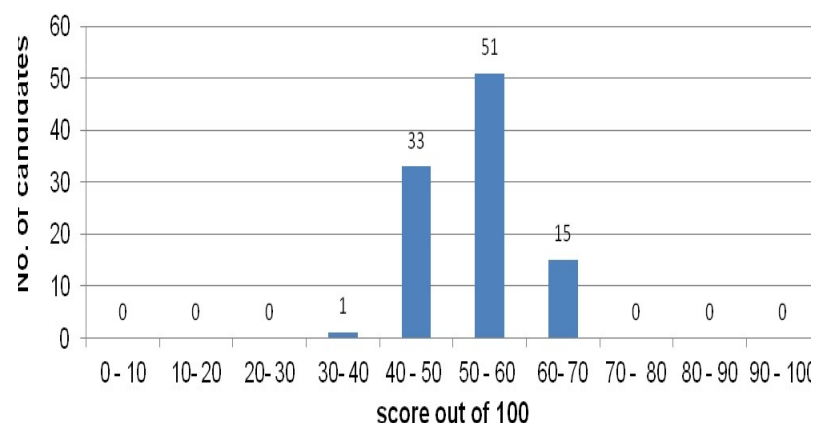

As shown in the graph, all the candidates are classified according to their SF- 36 score which shows that most of the candidates score between 50 to 60 points.

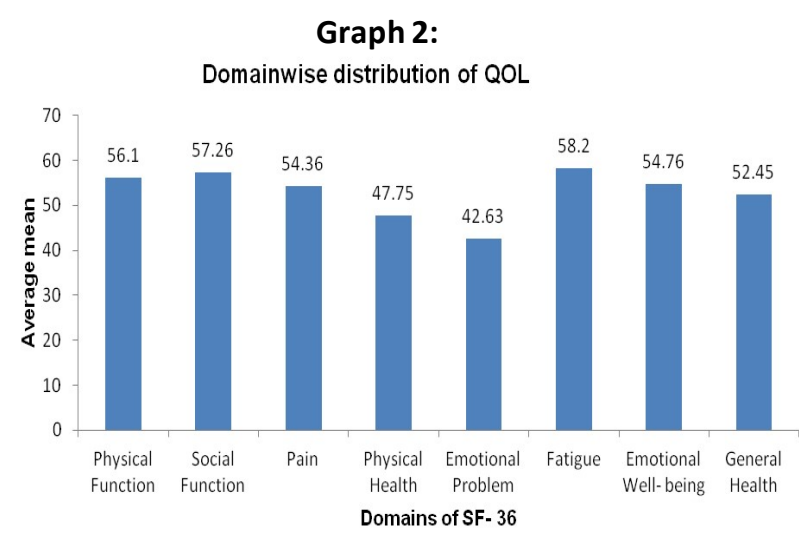

As shown in graph, domain wise distribution is done by taking into consideration the average mean of each domain of SF-36 questionnaire which showed that emotional problem domain has scored least marks.

Thus, results showed that average mean score of QOL of urban professional physiotherapists is $\mathbf{5 2 . 3 8}$ while most urban professional physiotherapists have QOL score (mode) of 53.85 with median of 52.44 .

\section{DISCUSSION}

In simplified language, quality of life can be defined as a gap between our expectations and experiences. It is a broader concept concerned with person's ability to fulfill a normal role. Regarding emotional health, though all professional physiotherapists are working under same external condition, author Carr concluded that each and every individual is on different emotional trajectory and our profession has a great impact on it as compare to general population [1]. In an urban area, environmental factors (pollution, transport mode, networking facilities) and working set up (working hours, deadlines, maintaining records) influences our emotions. With personalize experiences; some are able to find out the golden midpoint out of it to maintain work-life balance while some professional physiotherapists get dragged into it leading to symptoms like depression and anxiety further deteriorating their quality of life. Author Diener found in study that emotional health is consistently found to be associated with biological measures such as blood pressure, cortisol levels, inflam- 
-mation and immune system parameters affecting professional performances [4].

Physical health domain mainly includes performance of all daily physical activities without any physical pain and limitations. In urban professional physiotherapist, physical health is strongly influenced by lack of time to do physical exercise, bad ergonomics during clinical practice, disturbed sleep- awake cycle and availability of ready to use things. Author David found result from Almeda County study that individual with low physical activity levels are at increased risk for depression compared to those with high physical activity independent of the presence of chronic disease [5]. This suggest that emotional and physical health are interrelated to each other having influence on social, personal and professional commitments of urban professional physiotherapist.

\section{CONCLUSION}

This study concludes that QOL scores of urban professional physiotherapists remain mostly on lower side. Item analysis showed that emotional problem domain is severely affected (avg. mean $=42.63$ ) followed by physical health domain (avg. mean= 47.75).

\section{ABBREVIATIONS}

WCPT - The world Confederation for Physical Therapy.

\section{Conflicts of interest: None}

\section{REFERENCES}

[1]. Carr A, Gibson B, Robinson P. Is quality of life determined by expectations or experiences? BMJ 2001;322:1240-3.

[2]. Wu, S., Zhu, W., LI,H. et al. Quality of life and it's influencing factors among medical professionals in China. Int Arch Occup Environ Health 2010;83:753.

[3]. Cavallo P, Carpinelli L. Perceived stress and bruxism in university students. BMC Res Notes. 2016 Dec;21:514.

[4]. Diener E, Chan M. Happy people live longer: Subjective wellbeing contributes to health and longevity. IAAP 2011;3(1):1-43.

[5]. Brown D, Balluz L, Heath G, et al. Association between recommended levels of physical activity \& health related quality of life: Finding from the 2001Behavioural Risk Factor Surveillance System (BRFSS) survey. Preventive medicine 2003;37:520528.

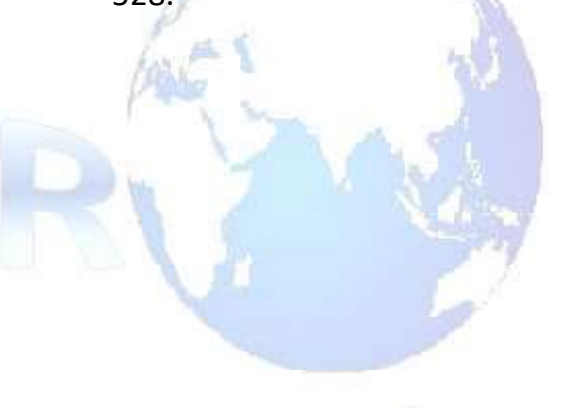

\section{QOL - Quality of life}

\section{How to cite this article:}

Nikita Vishnu Sawant, Jui Dave, Gauri Kulkarni. A CROSS SECTIONAL STUDY TO FIND OUT QUALITY OF LIFE OF URBAN PROFESSIONAL PHYSIOTHERAPISTS. Int J Physiother Res 2019;7(3):3066-3068. DOI: 10.16965/ ijpr.2019.119 